\title{
Differences in the Incidence of Gestational Diabetes between Women of Turkish and German Origin: An Analysis of Health Insurance Data From a Statutory Health Insurance in Berlin, Germany (AOK), 2005-2007
}

\author{
Unterschiede in der Gestationsdiabetesinzidenz im Vergleich zwischen türkischstämmigen \\ und deutschen Frauen: Eine Analyse von Abrechnungsdaten der AOK Berlin, 2005-2007
}

Authors

Affiliations
A. Reeske ${ }^{1}$, H. Zeeb ${ }^{1}$, O. Razum ${ }^{2}$, J. Spallek ${ }^{1,2}$

BIPS - Institute for Epidemiology and Prevention Research, Dept. of Prevention and Evaluation, Unit Social Epidemiology, Bremen

${ }^{2}$ University of Bielefeld, School of Public Health, Dept. of Epidemiology \& International Public Health, Bielefeld

\section{Key words}

- migration and health

- Turkey

- pregnancy

- perinatal health

- gestational diabetes

Schlüsselwörter

- Migration und Gesundheit

- Türkei

- Schwangerschaft

- perinatale Gesundheit

- Gestationsdiabetes $\begin{array}{ll}\text { received } & 24.10 .2011 \\ \text { revised } & 2.11 .2011 \\ \text { accepted } & 13.11 .2011\end{array}$

\section{Bibliography}

DOI http://dx.doi.org/

$10.1055 / \mathrm{s}-0031-1280428$

Geburtsh Frauenheilk 2012; 72

305-310 @ Georg Thieme

Verlag KG Stuttgart · New York

ISSN 0016-5751

\section{Correspondence}

\section{Anna Reeske, MSc}

BIPS - Institute for Epidemiology and Prevention Research

Dept. of Prevention and

Evaluation

Unit Social Epidemiology

Achterstraße 30

28359 Bremen

reeske@bips.uni-bremen.de

\section{Abstract \\ $\nabla$}

Background: Gestational diabetes increases the risk of maternal and infant complications and long-term health effects. A study of differences in the incidence of gestational diabetes between women of Turkish and German origin can identify high risk groups and may indicate the need for culturally sensitive diabetes information and treatment during pregnancy.

Method: We analysed all pregnancy related health insurance data from the AOK Berlin (a statutory health insurance in Berlin) based on data from 2005 to 2007, using a name algorithm to identify cases with Turkish migrant background. A group of German women insured with the AOK Berlin served as a comparison group.

Results: After exclusion of miscarriages and multiple births the data set comprised 3338 pregnancies in total. The incidence of gestational diabetes was significantly higher in women of Turkish origin with 183 per 1000 pregnancies than in German women (138 per 1000 pregnancies). Regression analyses showed that women of Turkish origin with obesity were at the highest risk of gestational diabetes ( $\mathrm{OR}=2.67 ; 95 \%$ confidence interval 1.97-3.60).

Conclusion: Obesity is an important factor in explaining the higher incidence of gestational diabetes in women of Turkish origin, especially among young Turkish women. These findings should stimulate discussion as to whether or not information about risk factors such as diabetes within the scope of prenatal care adequately addresses the needs of migrant women. Further research is needed to identify potential differences in undetected and primarily in insufficiently treated gestational diabetes between Turkish and German women.

\section{Zusammenfassung \\ $\nabla$}

Hintergrund: Gestationsdiabetes erhöht das mütterliche und kindliche Risiko für Komplikationen und nachhaltige Gesundheitsschäden. Eine Untersuchung von Unterschieden in der Inzidenz von Gestationsdiabetes zwischen türkischstämmigen und deutschen Frauen kann Risikogruppen identifizieren und auf einen erhöhten Bedarf an kultursensibler Diabetesaufklärung und -versorgung im Rahmen der Schwangerschaft hinweisen.

Methode: Ausgewertet wurden alle schwangerschaftsbezogenen Abrechnungsdaten von bei der AOK Berlin versicherten türkischstämmigen Frauen für den Zeitraum 2005-2007, die durch Anwendung eines Namensalgorithmus identifiziert wurden. Als Vergleichsgruppe diente eine Zufallsauswahl von bei der AOK Berlin versicherten deutschen Frauen.

Ergebnisse: Nach Ausschluss von Aborten und Mehrlingsgeburten wurden die Datensätze von insgesamt 3338 Schwangerschaften ausgewertet. Türkischstämmige Frauen hatten mit 183 pro 1000 Schwangerschaften eine signifikant höhere Gestationsdiabetesinzidenz als deutsche Frauen (138 pro 1000 Schwangerschaften). Regressionsanalysen zeigen, dass türkischstämmige Frauen mit Adipositas das höchste Risiko für Gestationsdiabetes hatten $(\mathrm{OR}=2,67$; 95\%-Konfidenzintervall 1,97-3,60).

Schlussfolgerung: Adipositas spielt eine wichtige Rolle in der Erklärung einer höheren Inzidenz von Gestationsdiabetes, besonders bei jüngeren türkischen Frauen. Diese Ergebnisse sollten eine Diskussion darüber anregen, ob die Aufklärung über Risikofaktoren wie Diabetes im Rahmen der Schwangerenvorsorge ausreichend auf die Bedürfnisse von Migrantinnen ausgerichtet ist. Weitere Forschung ist nötig, um mögliche Unterschiede im unerkannten und vor allem im unzureichend behandelten Gestationsdiabetes zwischen türkischen und deutschen Frauen zu untersuchen. 


\section{Background \\ 7}

Gestational diabetes is defined as a glucose intolerance that occurs or is detected for the first time during pregnancy [1]. A gestational diabetes that is recognised too late or not at all and therefore remains untreated significantly increases the infant's risk of intrauterine death, foetal macrosomia with diabetic fetopathy or premature birth $[2,3]$.The consequences of gestational diabetes during pregnancy for the mother include mainly hypertension caused by pregnancy and preeclampsia. Furthermore, there is the risk of a later manifestation of diabetes mellitus in the mother [1]. From the viewpoint of life course epidemiology [4] gestational diabetes also increases the risk of health-related damage in the child's later years, such as overweight and obesity in childhood and adolescence [5].

The German perinatal registry, which includes almost 99\% of births in German hospitals, reports 22000 cases of gestational diabetes for the year 2009 (3.4\% of all pregnancies) [6]. An estimated $90 \%$ of all gestational diabetes cases, however, are not detected at all, mainly because there is no routine screening for gestational diabetes as part of prenatal care in Germany [6]. The prevalence of gestational diabetes in Germany is estimated to be as high as $8 \%[3,7,8]$. In high risk groups - which may include women from migrant backgrounds - this is presumably even higher. A few studies from Germany and Austria indicate differences in the incidence of gestational diabetes between migrant women and the general population.

According to these studies women from Turkey, but also from eastern Europe and from the Mediterranean countries, seem to be particularly at risk $[7,9,10]$. Studies from the USA also identify clear ethnic differences in the prevalence of gestational diabetes with increased number of incidences primarily in women of Asian origin [11-13].

Amongst the risk factors for gestational diabetes, overweight and obesity have the greatest impact and at the same time also pose a particular challenge in terms of caring for expectant mothers [14]. These problems may be the result of a lack of physical activity and a diet that is too high in calories. Maternal age and the existence of gestational diabetes in a previous pregnancy are also important risk factors. In addition, there are indications that the ethnic background and type 2 diabetes in the family significantly increase the risk of gestational diabetes [15]. Ethnic differences in the occurrence of gestational diabetes may possibly be explained in part by differences in the prevalence of obesity [16,17]. In Germany obesity in female Turkish migrants is more prevalent than in the general population $[18,19]$.

This study is an investigation based on the records of the AOK Berlin, to determine whether there are any differences between Turkish and German women with regard to:

- the incidence of gestational diabetes,

- the frequency of selected risk factors for gestational diabetes,

- the birth outcomes of women with and without gestational diabetes.

\section{Methods \\ $\nabla$}

\section{Data records}

For the present study all pregnancy-related health insurance data of the AOK Berlin from the years 2005 to 2007 have been evaluated. We based our investigations on anonymised historical data of the insured, hospital case data and hospital diagnoses (original source: UB KH accounting results data) and outpatient diagnoses (original source: Association of Statutory Health Insurance Physicians). The expectant mothers insured year-round with the AOK Berlin were extracted from the total data set by an employee of the AOK Berlin using various pregnancy markers such as single pregnancy, multiple pregnancy or miscarriages. The information was complemented with details about the surviving (also) insured children. In the preliminary stages an extensive preparation of the data records was necessary, because the data of the AOK were contained in different Excel files, divided on one hand into those for the purpose of the different range of care provisions and on the other hand into ICD diagnoses and health services settled. As for the data from the hospitals, in general the hospital discharge diagnoses were used to determine the study population. However, since the diagnoses important to us were in part to be found in the main and secondary diagnoses, all three diagnosis categories had to be compared with one another and had to be amended. Following the plausibility check and preparation the different data records were combined by way of an individual pseudo-insured identification number.

Ethical approval was not required for this study, as the criteria of the "Good Practice Secondary Data Analysis" (GPS) of the German epidemiological associations was fulfilled. In accordance with this, in all phases of the study the regulations of data protection for secondary data analysis were observed. Anonymised data were used for the evaluation, so that a re-identification of persons was not possible.

\section{Inclusion/exclusion criteria}

The raw data set consisted of 4820 pregnancies. The main inclusion variable in this study was the diagnosis "single pregnancy" from the main, secondary or discharge diagnoses in the hospital records.

In this analysis the following data records were gradually excluded and have therefore not been taken into consideration:

- miscarriages, foetal deaths, stillborn infants (singletons), extrauterine pregnancies, hydatiform moles $(n=596)$,

- more than one pregnancy or settlement for one woman in the period 2005-2007 $(n=420)$,

- multiple pregnancies $(n=44)$,

- no non-ambiguous allocation of "singletons" possible $(n=4)$,

- mother older than 52 or younger than 15 at the time of birth $(n=5)$, or age missing $(n=196)$,

- inconclusive diagnosis of gestational diabetes $(n=217)$.

Ultimately the data of 3338 pregnancies of women insured with the AOK Berlin were included in the analysis.

\section{Definition of outcomes}

Gestational diabetes was identified in the diagnosis-related accounting data using the ICD Code 024.4, "Diabetes mellitus occurring during pregnancy".

The main problem here was the overlap with other diabetes diagnoses. For example, of the total number of 751 cases (20.4\%) with the diagnoses 024.4 only 534 (16.0\%) were included in the analysis as overlaps with the gestation-related diabetes diagnoses. The rest was excluded. "Diabetes mellitus in pregnancy, unspecified (024.9)" ( $n=59)$, "Diabetes mellitus in pregnancy: Already existing Diabetes mellitus type I (024.0)" $(n=20)$ or “Diabetes mellitus in pregnancy: Already existing Diabetes mellitus type 2 (O24.1)" ( $n=9)$ were present. Moreover, cases of gestational diabetes with the diagnoses "Type 1 diabetes" $(\mathrm{n}=114)$, "Type 2 dia- 
betes" $(n=34)$ or "Diabetes, unspecified" $(n=38)$ were also excluded. These cases were excluded because the chronology of the occurrence of the disease could not be determined.

We describe the incidence of gestational diabetes in this study as newly occurring cases of gestational diabetes per 1000 pregnancies in the period 2005 to 2007.

\section{Determining the migration background}

Since no reliable data about the migration background are recorded in the data of the AOK, a name algorithm was used to distinguish between women of Turkish origin and those of nonTurkish background, based on their first names and surnames.

The name algorithm consists of an SAS program that identifies definite and potential Turkish cases. In an additional "manual" part those cases that were identified as potentially Turkish were again individually checked and evaluated on site by a staff member of Turkish origin. The performance of the algorithm was determined in an earlier study by way of a manually produced gold standard which proved to be very reliable (sensitivity and specificity $>97.5 \%$ ] [20]. Further details about the algorithm are described elsewhere $[21,22]$. In order to comply with data protection the name algorithm was used under the direct supervision of the AOK Berlin. In this study we examine those persons whom we were able to identify as being of Turkish origin based on their names as persons with a Turkish migration background. They are referred to in the following as "of Turkish origin". As a comparison group a total of 2418 pregnancies of German women were selected by way of a pseudonymised insurance number from the database of the AOK Berlin. Defined as German were all those women identified as 'German' based on the AOK nationality tag and who were identified as "non-Turkish" according to the new origin characteristic of the name algorithm.

\section{Statistical analysis}

The data analysis was performed with the statistics program SAS (Statistical Analysis System, SAS Institute Inc., Version 9.2). Stratified analyses stem from the contingency tables. The characteristics were investigated using the $\mathrm{X}^{2}$ test for statistical associations. All computed p-values are two-sided. No corrections for multiple testing was used. The findings must therefore be regarded as purely descriptive.

In addition, binary logistic regression models were calculated for the probability of the occurrence of gestational diabetes and were adjusted for important risk factors. In a multiple model it was investigated whether the migration background has an independent impact on the occurrence of gestational diabetes after adjustments for the age of the mother and for obesity. Furthermore, one focus of the study was to assess the joint effect of migration background and obesity on the occurrence of gestational diabetes. Therefore an interaction term (migration status [of Turkish origin/German] * obesity [yes/no]) was created via a dummy variable. This was analysed on the one hand adjusted in the binary logistic model according to age and, on the other hand, stratified for the three age groups (under 25, 25-34, over 34). Further possible confounders, such as socio-economic status, could not be tested due to the large number of missing data or because the variables were not available in the data records.

\section{Findings}

The characteristics of the study population based on maternal origin are shown in $\odot$ Table 1. Significant differences between Turkish and German women appeared in the age distribution of the mothers. For example, the proportion of pregnant women under 25 was lower for the Turkish women compared with German women, while in the over 34 age group the proportion was slightly higher (nearly 16\%) than that for German women (15.5\%). The proportion of women with excessive weight gain or a preeclampsia during pregnancy, as well as the proportion of premature births, was significantly higher for Turkish women than for German ones. The prevalence of obesity (nearly 18\%) was slightly higher in Turkish women. No significant differences between Turkish and German mothers were found with regard to the diagnosis "overweight newborn" and the type of delivery.

- Table 2 shows the number of incident gestational diabetes cases and the incidence per 1000 pregnancies in the period 2005 to 2007 based on the mother's origin and stratifies according to selected risk factors and birth outcomes.

There was a significant difference in the total incidence between women of Turkish and German origin; for women of Turkish origin there were 183 per 1000 pregnancies in the period 2005 to

Table 1 Characteristics of the study population based on origin of the mother; accounting data from AOK Berlin, 2005-2007.

\begin{tabular}{|c|c|c|c|c|c|}
\hline & \multicolumn{2}{|c|}{ Turkish } & \multicolumn{2}{|c|}{ German } & \multirow[t]{2}{*}{ p value } \\
\hline & $\mathbf{n}$ & $\%$ & $\mathbf{n}$ & $\%$ & \\
\hline \multicolumn{6}{|c|}{ Age of the mother (in years) } \\
\hline Under 25 & 483 & 28.0 & 674 & 38.0 & $<0.001$ \\
\hline $25-34$ & 970 & 56.2 & 824 & 46.5 & \\
\hline Over 34 & 274 & 15.9 & 275 & 15.5 & \\
\hline \multicolumn{6}{|l|}{ Method of delivery } \\
\hline Spontaneous & 1308 & 75.4 & 1329 & 75.0 & 0.796 \\
\hline Forceps & 111 & 6.4 & 131 & 7.4 & \\
\hline Caesarian section & 308 & 17.8 & 313 & 17.7 & \\
\hline - Primary & 119 & 6.9 & 127 & 7.2 & \\
\hline - Secondary & 174 & 10.1 & 169 & 9.5 & \\
\hline - Other & 15 & 0.9 & 17 & 1.0 & \\
\hline \multicolumn{6}{|l|}{ Obesity } \\
\hline Yes & 307 & 17.8 & 282 & 15.9 & 0.139 \\
\hline No & 1420 & 82.2 & 1491 & 84.1 & \\
\hline \multicolumn{6}{|c|}{ Above-average weight gain during pregnancy } \\
\hline Yes & 77 & 4.5 & 56 & 3.2 & 0.044 \\
\hline No & 1650 & 95.5 & 1717 & 96.8 & \\
\hline \multicolumn{6}{|c|}{ Pre-eclampsia during pregnancy } \\
\hline Yes & 562 & 32.5 & 483 & 27.2 & $<0.001$ \\
\hline No & 1165 & 67.5 & 1290 & 72.8 & \\
\hline \multicolumn{6}{|c|}{ Newborn baby overweight } \\
\hline Yes & 54 & 3.1 & 56 & 3.2 & 0.957 \\
\hline No & 1673 & 96.9 & 1717 & 96.8 & \\
\hline \multicolumn{6}{|c|}{ Duration of pregnancy (in weeks) } \\
\hline $5-13$ & 25 & 1.5 & 48 & 2.7 & $<0.001$ \\
\hline $14-19$ & 13 & 0.8 & 26 & 1.5 & \\
\hline $20-25$ & 15 & 0.9 & 24 & 1.4 & \\
\hline $26-33$ & 19 & 1.1 & 46 & 2.6 & \\
\hline $34-36$ & 53 & 3.1 & 83 & 4.7 & \\
\hline $37-41$ & 1401 & 81.1 & 1257 & 70.9 & \\
\hline $41+$ & 178 & 10.3 & 190 & 10.7 & \\
\hline No details given & 23 & 1.3 & 99 & 5.6 & \\
\hline \multicolumn{6}{|c|}{ Premature birth (<26th week) } \\
\hline Yes & 312 & 18.1 & 251 & 14.2 & 0.001 \\
\hline No & 1415 & 81.9 & 1522 & 85.8 & \\
\hline
\end{tabular}


$2007(n=301)$ compared with 138 per 1000 pregnancies for German women $(n=233)(p<0.01)$. Examining the incidence stratified according to age, showed that the incidence is particularly high in the group of women of Turkish origin over 34 years of age compared with younger age groups and with German women (226 per 1000 pregnancies). There is a higher incidence of gestational diabetes in Turkish women with obesity (287 per 1000 pregnancies) and excessive weight gain during pregnancy (733 per 1000 pregnancies) compared with German women (194 and 278 per 1000 pregnancies, respectively). Despite significant differences in the proportion of premature birth, the incidence of gestational diabetes in women of Turkish origin is comparable with that of German women with a premature birth (130 per 1000 pregnancies).

The findings of the regression analyses are shown in $\square$ Table 3. The factor "Turkish origin of the mother" has a statistically significant impact on the existence of gestational diabetes both before and after adjustments for age and obesity. Women of Turkish ori-

Table 2 Frequency of gestational diabetes based on origin of mother, stratified for selected risk factors and pregnancy and birth outcomes; accounting data from AOK Berlin ( $n=3338)$.

\begin{tabular}{|c|c|c|c|c|}
\hline \multirow{2}{*}{$\begin{array}{l}\text { ICD code: } \\
\text { O24.4* }\end{array}$} & \multicolumn{2}{|c|}{ Turkish (n=1647) } & \multicolumn{2}{|c|}{ German ( $n=1691)$} \\
\hline & $\begin{array}{l}\text { New } \\
\text { cases }\end{array}$ & $\begin{array}{l}\text { Incidences } \\
\text { per } 1000^{*}\end{array}$ & $\begin{array}{l}\text { New } \\
\text { cases }\end{array}$ & $\begin{array}{l}\text { Incidences } \\
\text { per } 1000^{*}\end{array}$ \\
\hline Total & (301) & 183 & (233) & 138 \\
\hline \multicolumn{5}{|l|}{ Maternal age } \\
\hline Under 25 & (73) & 159 & (73) & 112 \\
\hline $25-34$ & (169) & 182 & (119) & 152 \\
\hline Over 34 & (59) & 226 & $(41)$ & 158 \\
\hline \multicolumn{5}{|c|}{ Method of delivery } \\
\hline Spontaneous* & (237) & 189 & (165) & 131 \\
\hline Forceps & $(16)$ & 157 & (17) & 132 \\
\hline Caesarian section & (48) & 165 & (51) & 171 \\
\hline Primary & (17) & 155 & (13) & 109 \\
\hline - Secondary & (26) & 157 & (33) & 201 \\
\hline Other & (5) & 333 & (5) & 313 \\
\hline \multicolumn{5}{|l|}{ Obesity } \\
\hline Yes & (83) & 287 & (52) & 194 \\
\hline No & (218) & 161 & (181) & 127 \\
\hline \multicolumn{5}{|c|}{ Above-average weight gain during pregnancy } \\
\hline Yes & $(55)$ & 733 & (15) & 278 \\
\hline No & $(246)$ & 157 & $(218)$ & 133 \\
\hline \multicolumn{5}{|c|}{ Pre-eclampsia during pregnancy } \\
\hline Yes & $(115)$ & 213 & (79) & 172 \\
\hline No & $(186)$ & 168 & $(154)$ & 125 \\
\hline \multicolumn{5}{|c|}{ Newborn baby overweight } \\
\hline Yes & $(13)$ & 260 & $(14)$ & 255 \\
\hline No & $(288)$ & 180 & (219) & 134 \\
\hline \multicolumn{5}{|c|}{ Duration of pregnancy (in weeks) } \\
\hline $5-13$ & (7) & 280 & (4) & 83 \\
\hline 14-19 & (1) & 83 & (3) & 115 \\
\hline $20-25$ & (5) & 333 & (0) & 0 \\
\hline $26-33$ & $(2)$ & 111 & (9) & 200 \\
\hline $34-36$ & (15) & 294 & (9) & 110 \\
\hline $37-41$ & (241) & 181 & $(172)$ & 144 \\
\hline $41+$ & $(26)$ & 154 & $(29)$ & 161 \\
\hline No details given & (4) & 182 & (7) & 75 \\
\hline \multicolumn{5}{|c|}{ Premature birth (<26th week) } \\
\hline Yes & (39) & 132 & (33) & 136 \\
\hline No & $(262)$ & 194 & $(200)$ & 138 \\
\hline
\end{tabular}

* New cases of gestational diabetes per 1000 pregnancies from 2005-2007 gin had a 40 percent higher probability of gestational diabetes than German women $(\mathrm{OR}=1,4 ; 95 \% \mathrm{Cl}=1.12-1.63)$. In addition, the probability of gestational diabetes increases with age. The single largest factor for the occurrence of gestational diabetes was obesity $(\mathrm{OR}=1.9 ; 95 \% \mathrm{CI}=1.5-2.4)$. As the descriptive findings point to an assiciation between Turkish origin and obesity, we investigated the impact of this possible interaction on the risk for gestational diabetes in a regression model ( Table 3). Adjusted for maternal age, Turkish women with obesity had the highest probability of developing gestational diabetes, compared with German women without obesity $(\mathrm{OR}=2.67)$. The odds ratio was higher than in German women with obesity $(\mathrm{OR}=1.66)$ and even significantly higher compared with Turkish women without obesity ( $O R=1.3$ ). A further age stratification shows that, compared with the other age groups, primarily obese women of Turkish origin under the age of 25 had a clearly increased chance of developing gestational diabetes (data not presented).

\section{Discussion}

This study is the first to describe the occurrence of gestational diabetes comparing Turkish and German women in Germany based on statutory health insurance data from the AOK Berlin. Besides known risk factors for the incidence of gestational diabetes, such as age or obesity of the mother, being of Turkish origin is shown to be another independent risk factor. The risk of women of Turkish origin is particularly increased if they are obese.

On the basis of data from the period 2005 to 2007 we were able to establish significant differences between women of Turkish origin and women of German origin in terms of the incidence of gestational diabetes. This finding is consistent with other studies from Germany and Austria [7,9-10]. Moreover, our evaluation points to a particular group at risk of gestational diabetes: young,

Table 3 Influence of origin on gestational diabetes, adjusted for key risk factors (results of simple and multiple logistic regression).

\begin{tabular}{|c|c|c|c|c|}
\hline & \multicolumn{2}{|c|}{ Simple log. regression } & \multicolumn{2}{|c|}{ Multiple log. regression } \\
\hline & $\begin{array}{l}\text { Crude } \\
\text { OR }\end{array}$ & $95 \% \mathrm{Cl}$ & $\begin{array}{l}\text { Adjusted } \\
\text { OR }\end{array}$ & $95 \% \mathrm{Cl}$ \\
\hline \multicolumn{5}{|c|}{ Origin of the mother } \\
\hline Turkish & 1.40 & $1.16-1.69$ & 1.35 & $1.12-1.63$ \\
\hline German & 1 & & 1 & \\
\hline \multicolumn{5}{|c|}{ Maternal age (in years) } \\
\hline Under 25 & 1 & & 1 & \\
\hline $25-34$ & 1.34 & $1.09-1.66$ & 1.28 & $1.03-1.59$ \\
\hline Over 34 & 1.57 & $1.19-2.08$ & 1.51 & $1.14-2.00$ \\
\hline \multicolumn{5}{|l|}{ Obesity } \\
\hline Yes & 1.91 & $1.53-2,38$ & 1.89 & $1.51-2.35$ \\
\hline No & 1 & & 1 & \\
\hline \multicolumn{5}{|c|}{ Origin* Obesity* } \\
\hline $\begin{array}{l}\text { Turkish with } \\
\text { obesity }\end{array}$ & 2.77 & $2.05-3.73$ & 2.67 & $1.97-3.60$ \\
\hline $\begin{array}{l}\text { Turkish with- } \\
\text { out obesity }\end{array}$ & 1.31 & $1.06-1.62$ & 1.29 & $1.18-2.34$ \\
\hline $\begin{array}{l}\text { German with } \\
\text { obesity }\end{array}$ & 1.65 & $1.18-2.32$ & 1.66 & $1.04-1.59$ \\
\hline $\begin{array}{l}\text { German with- } \\
\text { out obesity }\end{array}$ & 1 & & 1 & \\
\hline
\end{tabular}

\footnotetext{
* Also adjusted for the age of the mother
} 
Turkish women with obesity had the highest chance of developing gestational diabetes.

The interpretation of the differences in the occurrence of gestational diabetes is subject to limitations resulting mainly from the structure of the data records. Because the data of the health insurers are collected for purposes other than scientific evaluation, important information such as socio-demographic and anamnestic data is partly missing. It was therefore not possible, for instance, to include the potential impact of the socio-economic status of the expectant mothers on the occurrence of gestational diabetes in this analysis. Furthermore, information about other important risk factors for gestational diabetes, such as data relating to miscarriages, a family history of diabetes mellitus type 2 or whether gestational diabetes was already present in a previous pregnancy, is also lacking. Hence, it cannot be ruled out that the increased gestational diabetes incidence in migrants of Turkish origin in our study is due to an increased prevalence of other risk factors for gestational diabetes in this group which has not been investigated here. A further uncertain factor is the unverifiable validity and precision of the documentation of certain information. The insurance accounting data, especially in the outpatient area, are based on the documentation of physicians and therefore dependent on their coding behaviour. Hence, when using "accounting diagnoses" clear inclusion and exclusion criteria for the investigated population must be stated [23]. In our study we have chosen a conservative method and have excluded all women who had more than one ICD code for a diabetes diagnosis or had inconclusive diagnoses. A further validation of the diagnoses was not possible in this study. Notable in our study is the very high incidence of preeclampsia. In this respect an overestimation appears possible, which may be connected with the coding behaviour of physicians. However, we have no indication that this potential distortion differs in frequency between the Turkish or the German study subjects. The comparisons between the two groups are therefore valid. The data is only representative of women living in Berlin and insured through the AOK. Applying these results to the entire population is not possible on the basis of this study, as the study population may differ from the general population in terms of socio-economic and other individual factors.

Despite these methodological limitations this study also has several strengths. We had person-related instead of case-related data - as in most routinely collected data sets. Hence we were able to combine and evaluate all relevant information relating to the individual across all sectors. In addition to this the risk of systematic selection effects is comparatively low. This can be ascribed on the one hand to the high degree of completeness in relation to the target population. For example, in this study all Turkish women insured with the AOK Berlin in the period 2005 to 2007 with a live-born singleton infant were included. On the other hand, because of the routine documentation type bias due to selective non-responses of the study population or bias through selective information given by study participants can be ruled out for the most part [24]. The data of the AOK Berlin do not contain any information on the migration background of the insured women. One of the strengths of this study is the use of a name algorithm to differentiate between Turkish and non-Turkish origin, whereby women of Turkish origin but with German citizenship could be included, and the fact that this information could be used in connection with the diagnoses of gestational diabetes and potential risk factors.
We were able to show that obesity plays an important role in explaining the higher incidence of gestational diabetes, especially in young women of Turkish origin. Targeted preventive measures for these women should start before a pregnancy or, at the very latest, at the beginning of a pregnancy. Furthermore, this should be an important target group for receiving specific information on gestational diabetes provided by the gynaecologists accompanying the pregnancy as part of prenatal care. Even if Turkish migrant women do not necessarily attend prenatal care less frequently, there are indications for deficits in the care process of prenatal care for foreign women [25]. Here, language problems and differences in the understanding of health and disease on the part of expectant mothers with a migration background represent important barriers which may be detrimental to the care process. As the care of patients with (gestational) diabetes demands thorough education and high compliance, future studies should investigate whether the differences in the incidence of gestational diabetes and subsequent birth outcomes between migrant women and non-migrant women are due to barriers to the provision of care or deficits in prenatal care, that might be associated with a reduced adherence and compliance among women of Turkish origin.

\section{Acknowledgement \\ $\nabla$}

We would like to thank Henry Kotek and Manfred Jebram of the AOK Berlin for compiling the data and making this available to us. We also wish to thank Kai Kolpatzik of the AOK Bundesverband for his support of the project.

\section{Conflict of Interest}

$\nabla$

This study was funded by the AOK Bundesverband as part of a project on perinatal health of children with a migrant background in Germany. The AOK Bundesverband had no influence on the development of either the research question or the data analysis and interpretation.

\section{References}

1 Kainer F. Gestationsdiabetes. In: Dudenhausen JW, Schneider HPG, Bastert G, Hrsg. Frauenheilkunde und Geburtshilfe. Berlin: Walter de Gruyter; 2003: 186-189

2 Plagemann A, Harder T, Dudenhausen JW. Mechanismen perinataler Programmierung am Beispiel der Körpergewichts- und Stoffwechselregulation. Gynäkologe 2007; 40: 248-255

3 Weiss PA, Walcher W, Scholz HS. Der vernachlässigte Gestationsdiabetes: Risiken und Folgen. Geburtsh Frauenheilk 1999; 59: 535-544

4 Kuh D, Ben-Shlomo Y, Hrsg. A Life-Course Approach to chronic Disease Epidemiology. New York: Oxford University Press; 2005

5 Boney CM, Verma A, Tucker $R$ et al. Metabolic syndrome in childhood: association with birth weight, maternal obesity, and gestational diabetes mellitus. Pediatrics 2005; 115: e290-e296

6 Kleinwechter H, Schäfer-Graf U. Diabetes und Schwangerschaft. In: diabetesDE, Hrsg. Deutscher Gesundheitsbericht. Diabetes 2011. Mainz: Kirchheim Verlag; 2011: 131-138

7 Bühling KJ, Stein U, Dudenhausen J. Evaluation des $50 \mathrm{~g}$-Glukose-Screeningtests an 1416 Schwangeren. Geburtsh Frauenheilk 1998; 58: 100 109

8 Festa A, Schwarzmaier A, Bechter B et al. Anwendung eines sensitiven Verfahrens zur Diagnostik des Gestationsdiabetes. Metabolische und klinische Ergebnisse. Geburtsh Frauenheilk 2001; 61: 79-84

9 Schneider S, Hoeft B, Freerksen $N$ et al. Neonatal complications and risk factors among women with gestational diabetes mellitus. Acta Obstet Gynecol Scand 2010; DOI: 10.1111/j.1600-0412.2010.01040.x 
10 Tammaa A, Teich G, Scholl T et al. Ethnologie als Risikofaktor für Gestationsdiabetes in Mitteleuropa. Geburtsh Frauenheilk 2001; 61: 142146

11 Thorpe LE, Berger D, Ellis JA et al. Trends and racial/ethnic disparities in gestational diabetes among pregnant women in New York City, 19902001. Am J Public Health 2005; 95: 1536-1539

12 Rosenberg TJ, Garbers S, Lipkind $\mathrm{H}$ et al. Maternal obesity and diabetes as risk factors for adverse pregnancy outcomes: differences among 4 racial/ethnic groups. Am J Public Health 2005; 95 : 1545-1551

13 Mocarski M, Savitz DA. Ethnic differences in the association between gestational diabetes and pregnancy outcome. Matern Child Health J 2011; DOI: 10.1007/s10995-011-0760-6

14 Hartge DR, Dawson A, Bohlmann MK et al. Gravidas with a BMI above 25: challenges in antenatal and peripartal monitoring. Geburtsh Frauenheilk 2010; 70: 463-471

15 Galtier F. Definition, epidemiology, risk factors. Diabetes Metab 2010; 36: 628-651

16 Green JR, Pawson IG, Schumacher LB et al. Glucose tolerance in pregnancy: ethnic variation and influence of body habitus. Am J Obstet Gynecol 1990; 163: 86-92

17 Straube S, Voigt M, Hesse Vet al. Comparison of anthropometric characteristics of German-born vs. Asian-born mothers and their neonates an analysis of the German perinatal survey (19th communication). Geburtsh Frauenheilk 2010; 70: 472-477

18 Razum O, Zeeb H, Meesmann U et al.; Robert Koch-Institut, Hrsg. Migration und Gesundheit. Schwerpunktbericht der Gesundheitsberichterstattung des Bundes. Berlin: Robert Koch-Institut; 2008
19 Reeske A, Spallek J, Razum O. Changes in cardiovascular risk factors among first and second generation Turkish migrants in Germany - an analysis of the Mikrozensus 2005. Eur J Public Health 2007; 17 (Suppl. 2): 64

20 Spallek J, Kaatsch P, Spix C et al. Namensbasierte Identifizierung von Fällen mit türkischer Herkunft im Kinderkrebsregister Mainz. Gesundheitswesen 2006; 68: 643-649

21 Razum O, Zeeb H, Akgün S. How useful is a name-based algorithm in health research among Turkish migrants in Germany? Trop Med Int Health 2001; 6: 654-661

22 Razum O, Zeeb H, Beck K et al. Combining a name algorithm with a capture-recapture method to retrieve cases of Turkish descent in a German population-based cancer registry. Eur J Cancer 2000; 36: 23802384

23 Schubert I, Köster I, Küpper-Nybelen J et al. Versorgungsforschung mit GKV-Routinedaten. Bundesgesundheitsbl 2008; 51: 1095-1105

24 Hoffmann F, Andersohn F, Giersiepen K et al. Validierung von Sekundärdaten. Bundesgesundheitsbl 2008; 51: 1118-1126

25 Tadesse R, Jahn A, Razum 0 . How well do doctors document their findings in antenatal care - and are there differences between women of German and non-German nationality? 5. Arbeitstagung der FIDE 1999

Deutschsprachige Zusatzinformationen mit deutschem Text online abrufbar unter: www.thieme-connect.de/ejournals/toc/gebfra. 